\title{
KECERDASAN EMOSIONAL DAN LEADER MEMBER EXCHANGE SEBAGAI FAKTOR PEMICU KINERJA KARYAWAN
}

\section{Oleh :}

Senny Handayani Suarsa

Program Studi Manajemen Perusahaan - Politeknik Pos Indonesia

Email : sennyhandayani@ poltekpos.ac.id

Asaretkha Adjane Annisawati

Adrian Fadillah

\begin{tabular}{|c|c|}
\hline Article Info & Abstract \\
\hline $\begin{array}{l}\text { Article History: } \\
\text { Received } 29 \text { July - } 2020 \\
\text { Accepted } 20 \text { August - } 2020 \\
\text { Available Online } \\
\text { O7 Sept - } 2020\end{array}$ & $\begin{array}{l}\text { This study are expected to get an overview of Emotional } \\
\text { Intelligence (EI), Leader Member Exchange (LMX), Employee } \\
\text { Performance (EP) and the influence of EI and LMX on EP. Besides, } \\
\text { this reference can be used for Auto } 2000 \text { to determine how to } \\
\text { manage the EI of its employees with the situation of leadership } \\
\text { changes in their divisions in the future. Data were collecting } \\
\text { through a saturated survey method involving } 30 \text { respondents and } \\
\text { processing through validity and reliability, descriptive analysis, } \\
\text { Ttest and Ftest, and regression. The results had a significant and } \\
\text { positive influence on the performance of Auto } 2000 \text { Asia Afrika } \\
\text { Bandung employees. Thus the hypothesis is proven. }\end{array}$ \\
\hline $\begin{array}{l}\text { Keyword: } \\
\text { Emotional Intelligence } \\
\text { (EI), Leader Member } \\
\text { Exchange } \quad \text { (LMX), } \\
\text { Employee Performance } \\
(\text { EP), Auto 2000. }\end{array}$ & \\
\hline
\end{tabular}




\section{PENDAHULUAN}

Konsep Manajemen Sumber Daya Manusia (MSDM) telah mengalami beberapa perubahan diantaranya adalah organisasi memandang Sumber Daya Manusia (SDM) sebagai asset perusahaan yang bernilai, bukan hanya sebagai manusia yang dipekerjakan dan diberi upah (Kasmawati, 2018). Pada dasarnya SDM dan perusahaan memiliki kesatuan yang saling membutuhkan, walaupun di era digital sekarang ini, sudah banyak tenaga manusia yang telah digantikan oleh mesin otomatis berteknologi canggih. Namun demikian sampai sekarang tidak ada perusahaan atau organisasi yang melaksanakan tugas-tugasnya tanpa bantuan dari SDM. Melalui pemanfaatan SDM yang baik inilah maka operasional perusahaan diharapkan berjalan dengan baik secara efisien dan efektif (Rouf, 2018). Untuk itu, salah satu kunci pokok yang perlu dipelihara dan diperhatikan adalah keberadaan SDM-nya (Setiawan, 2016). Namun demikian, masih banyak perusahaan yang belum memanfaatkan SDM yang dimilikinya dengan baik, sehingga tujuan perusahaan menjadi tidak tercapai dengan maksimal. Salah satu indikator pencapai tujuan perusahaan adalah kinerja karyawan yang baik. Untuk itu, dangan memberhatikan dan mengatur keberadaan SDM-nya tersebut merupakan salah satu usaha perusahaan agar dapat mencapai tujuan usahanya.

Auto 2000 Asia Afrika Bandung adalah perusahaan jasa dalam bidang penjualan dan pemeliharaan kendaraan. Dalam pelaksanaan kegiatan operasionalnya, perusahaan harus memperhatikan aspek kecepatan, ketepatan, dan kecermatan dalam melayai pelanggan terutama di bagian pemeliharaan kendaraan baik pemeliharaan berkala maupun perbaikan sesuai keluhan pelanggan. Tingkat persaingan yang tinggi menuntut perusahaan dapat mencapai target perusahaan. Keberhasilan perusahaan untuk mencapai target dipengaruhi oleh kinerja karyawannya (Latief, 2012; Wardhana, Tarmedi, \& Sumiyati, 2016) sehingga perusahaan akan berusaha untuk mengoptimalkan prestasi kerja para karyawannya. Harapannya adalah pencapaian tujuan perusahaan.

Kinerja karyawan dalam perusahaan tidak selalu stabil, kadang naik dan kadang turun dan banyak faktor yang mempengaruhinya, dan kecerdasan emosional merupakan salah satu faktor dari dalam individu yang berpengaruh terhadap kinerja karyawan (Hanzaee \& Mirvaisi, 2013; Suryana, 2014; Yunus, Ishak, Mustapha, \& Othman, 2010) sementara hubungan karyawan dengan pimpinan merupakan faktor dari luar yang berpengaruh terhadap kinerja karyawan (Farahbod, Azadehdel, Rezaei-Dizgah, \& Nezhadi-Jirdehi, 2012; Ibrahim, Ghani, \& Salleh, 2013; Ilies, Nahrgang, \& Morgeson, 2007; Yunus et al., 2010). Dalam studi ini berdasar dari beberapa penelitian sebelumnya mencoba menggabungkan dan meneliti kembali pengaruh kecerdasan emosional (emotional intelligence/EI), leader member exchange $(L M X)$, dan kinerja karyawan (employee performance/EP).

Fenomena yang terjadi pada karywan Auto 2000 Asia Afrika Bandung menunjukkan adanya permasalahan dari sisi $E I, L M X$ terhadap $E P$. Penulis melakukan wawancara awal kepada 30 orang karyawan sales unit. Hasilnya didapatkan bahwa 24 karyawan mengakui bahwa adanya ketidakstabilan emosi pada saat bekerja di waktu tertentu. Sebagian besar karyawan sales unit menjadi mudah emosi ketika pekerjaan yang dikerjakan sesuai target harus lebih cepat diselesaikan guna menguntungkan perusahaan. Hal ini menjadi tambahan beban emosi dari sebagian besar karyawan sales unit yang diwawancara

Dalam hal $L M X$ fenomena yang terjadi adalah kualitas interpersonal antara pekerja dan pimpinannya. Penulis telah melakukan wawancara awal kepada semua karyawan sales unit untuk mengetahui hubungan interpersonal karyawan sales unit terhadap pimpinan lama dan juga pimpinan yang baru. Dari 30 orang karyawan yang diwawancara, 24 orang berpendapat bahwa pekerjaan mereka selama ini telah diapresiasi oleh atasan, sedangkan 6 orang lainnya mengaku kurang menyukai atasan yang baru.

Hal ini menurut mereka terjadi karena, atasan lama mereka selalu menekan untuk berkerja lebih keras tanpa memperdulikan usaha karyawan. Karyawan selalu dituntut untuk mencapai hasil kerja melebihi target yang bisa dicapai. Hal ini sangat berbeda dengan pendapat karyawan terhadap pimpinan yang baru. Dari 30 orang yang diwawancara, 24 diantaranya mengaku senang terhadap pimpinan baru dikarenakan pimpinan baru lebih respect, ramah, dan mempercayai bawahannya, sehingga mereka menjadi lebih hormat, loyal, dan mereka bersemangat untuk terus berkontribusi terhadap 
perusahaan. Tidak adanya komunikasi timbal balik yang baik dan jelas pada periode pimpinan lama juga menimbulkan kecurigaan antara sesama rekan kerja ataupun terhadap pimpinan yang lama.

Dalam hal EP, terdapat fenomena yang menunjukkan adanya peningkatan setelah pergantian pimpinan yang baru yang membuat kinerja dari sales unit menjadi membaik dari sebelumnya. Ini menunjukkan terdapat pengaruh yang ditimbulkan dari pergantian pimpinan yang baru yang berakibat pada pengendalian $E I$. Salah satu indikator dari $E P$ adalah kuantitas kerja. Aspek target penjualan adalah salah satu penilaian dari indikator kuantitas kerja. Berdasarkan data dilapangan, terdapat beberapa target penjualan unit mobil yang dikategorikan berdasarkan best seller pada periode waktu tersebut pada bulan Oktober hingga Desember pada periode pimpinan lama dan bulan Januari hingga Maret pada periode pimpinan yang baru

\section{Gambar 1.}

\section{Penjualan unit Best Seller per 3 Bulan}

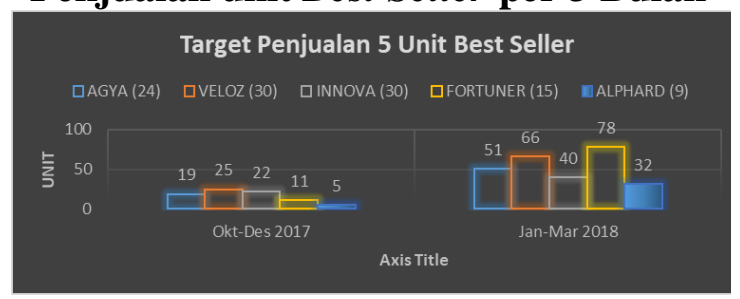

Sumber: hasil olahan Penulis, 2020

Gambar tersebut menunjukkan EP selama transisi pimpinan lama ke pimpinan baru. Penjualan pada lima kategori unit best seller yaitu merek Agya, Veloz, Innova, Fortuner, dan Alphard.

Dalam wawancara awal penulis dengan 30 karyawan sales unit, 24 berpendapat bahwa angka target sangat sulit dicapai jika dalam keadaan emosional yang tinggi, kinerja mereka pada saat menjual unit kepada calon pembeli menjadi kurang optimal yang berakhir pada pembatalan pembelian unit dari calon pembeli dikarenakan karyawan yang sedang dalam keadaan kurang ramah. Hal ini berbanding terbalik pada periode pimpinan baru dimana target penjualan meningkat. Hal ini dapat dilihat bahwa kualitas $E I$ dan hubungan timbal balik karyawan dan atasan mengenai kinerja karyawan mempengaruhi EP sales unit yang dilihat dari target penjualan yang ditentukan perusahaan.

Pergantian pimpinan yang sering terjadi secara teoritis dapat mengakibatkan kinerja karyawan menjadi kurang efektif (Supit, Suryawati, \& Sriatmi, 2015; Suprihati, 2014). Pada sisi lainnya pimpinan juga cenderung tidak memperhatikan fungsi dan tugas pokok karyawan dalam pelaksanaan program kerja (Supit et al., 2015). Kondisi ini menyebabkan motivasi untuk bekerja menjadi turun/rendah. Dari sisi kinerja juga bisa dilihat dari waktu bekerja. Sekitar 30 orang karyawan sales unit, rata-rata yang terlambat (> pkl 8.00 yaitu 17-18 pegawai perbulan pada periode pimpinan lama, sedangkan yang pulang lebih awal $(<$ pkl 17.00 yaitu 20-21 pegawai perbulan. Rata-rata yang hadir ke kantor hanya 60 persen saja, sisanya mangkir dengan berbagai alasan. Hal ini berbeda dengan periode pimpinan yang baru. Dari 30 orang karyawan sales unit, rata rata yang datang terlambat (> pkl 8.00 atau 4-6 pegawai perbulan pada periode pimpinan lama, demikian pula yang pulang awal (< pkl 17.00 yaitu 6-7 karyawan perbulan. Rata-rata yang hadir ke kantor 87 persen, sisanya mangkir kerja.

Sebagai salah satu perusahaan besar, sangatlah di butuhkan partisipasi aktif dan kerjasama antar rekan kerja. oleh karena itu perlu memunculkan EI dan LMX guna meningkatkan EP demi tercapainya tujuan perusahaan. Saling membantu dan bekerja diluar Job desk sangatlah di perlukan pada organisasi guna memberikan pelayanan yang maksimal.

Tujuan penelitian ini untuk mengetahui Emotional Intelligence dan LMX terhadap Employee Performance sales unit di Auto 2000 Asia Afrika Bandung.

\section{KERANGKA PEMIKIRAN DAN PEGEMBANGAN HIPOTESIS \\ Kecerdasan Emosional \\ (Emotional Intelligence)}

Ungkapan Emotional Intelligence (EI) pertama kali digunakan oleh Payne (1985) dan dianggap menunjukkan kemampuan seseorang untuk berhubungan dengan rasa takut, rasa sakit dan keinginan (Hanzaee \& Mirvaisi, 2013). Sedangkan (Saphiro, 1997) mendefinisikan EI adalah kecerdasan sosial yang mampu memantau perasaan sosial untuk melakukan pemilahan dan menggunakan informasi sehingga dapat melakukan tindakan. Dalam pengaturan profesional (Singh, 2001) berpendapat bahwa $E I$ memfasilitasi manajer dan karyawan untuk mengidentifikasi dan menyadari emosi serta mengaplikasikannya dalam mengelola diri dan hubungan mereka dengan orang lain. Sedangkan (Cooper dan 
Sawaf, 2002) mendefinisikan EI sebagai tindakan seseorang yang didasarkan pada kecerdasan sosial yang melibatkan perasaan dalam memilih dan menggunakan informasi yang dimilikinya. Emosi mempengaruhi seseorang berfikir lebih cerdas (Fauziah, 2015). Dari definisi-definisi tersebut dapat ditafsirkan bahwa EI sangat erat kaitannya dengan pengarahan tindakan yang dilakukan individu secara pribadi atau sosial sehingga dapat mengembangkan emosi dan intelektualnya (Sumiyarsih, Mujiasih, \& Ariati, 2012).

Disamping itu, Baron mendefinisikan EI sebagai kemampuan pribadi, baik secara emosi dan sosial seorang individu sehingga dapat berhasil mengatasi tekanan dan tuntutan lingkungan (Ciarrochi \& Kashdan, 2013). EI secara relatif merupakan kesadaran seseorang terhadap emosinya sendiri (Winarno, 2008) dan kemampuannya untuk bisa mengekspresikan emosi-emosinya dan untuk menggunakan emosi tersebut (Pambudi, 2014).

\section{Dimensi dan Indiktor Kecerdasan Emosional (Emotional Intelligence)}

Menurut (Cooper dan Sawaf, 2002), dimensi EI terdiri dari perasaan (emosi), pikiran dan kesadaran, meliputi:

\section{Self Awarness}

Kesadaran diri artinya mampu mengetahui dan merasakan apa yang sedang terjadi dan waspada, agar tidak terbawa emosi yang menggebu-gebu. Ini merupakan inti $E I$, apabila seseorang ingin mengembangkan $E I$, maka perlu dimulai dengan meningkatkan kesadaran diri.

2. Self Control

Seseorang dapat dikatakan mampu mengendalikan diri apabila dia dapat mengekspresikan dan mengengelola emosinya. Kemampuan dalam mengatur emosinya ini dapat berdampak positif pada pelaksanaan tugas-tugasnya diperusahaan.

3. Motavasi (Motivation)

Merupakan kemampuan dalam menggunakan naluri untuk bergerak menuju sasaran perusahaan. Mengendalikan emosi erat kaitannya dengan motivasi diri.

\section{Empathy}

Kemampuan merasakan dan memahami perasaan orang lain. Diantaranya, kemampuan mendengar, peka terhadap perasaan orang lain dan apa yang dibutuhkannya.

\section{Social Skills}

Ketika berhubungan dengan orang lain, dia mampu mengatur emosinya dengan baik, dapat membaca situasi secara cermat, dan bekerjasama dengan baik.

\section{Leader Member Exchange (LMX)}

Yaitu hubungan antara pimpinan dan bawahannya (Lengkong, Lapian, \& Lengkong, 2016). LMX didefinisikan oleh (Graen \& UhlBien, 1995) sebagai kualitas hubungan interpersonal antara atasan dan bawahannya. Sementara (Graen \& Uhl-Bien, 1995) berpendapat bahwa atasan mempengaruhi karyawan melalui kualitas hubungan yang baik. Hal ini dapat berupa rasa hormat, profesionalisme kerja, kepercayaan, dan loyalitas.

Kesimpulannya, LMX merupakan interaksi sosial antara atasan dan bawahan dapat berupa jasa, afiliasi, status, barang, informasi, dan uang untuk mendapatkan hubungan dan dukungan yang baik.

\section{Dimensi $L M X$}

Dalam penelitian (Graen \& Uhl-Bien, 1995) dimensi $L M X$ adalah:

1) Loyalty: kesetiaan atasan kepada bawahan dalam situasi dan kondisi apapun.

2) Contribution yaitu persepsi kuantitas dan kualitas aktifitas kerja untuk mencapai tujuan bersama yang saling menguntungkan.

3) Affect: bentuk kepedulian antara atasan dan bawahan karena kepribadian yang dimiliki.

4) Professional Respect yaitu sejauh mana setiap hubungan yang telah dimiliki dapat membangun reputasi baik mengenai urusan pribadi maupun professional sehingga dapat meningkatkan kompetensi di bidang kerjanya.

\section{Kinerja Karyawan (Employee Performance)}

Employee Performance (EP) merupakan pencapaian seorang pegawai secara kualitas dan kuantitas sesuai dengan tugas dan tanggung jawab yang diberikan kepadanya (Indarjanti \& Bodroastuti, 2012; Mangkunegara, 2002). Suatu kinerja dapat behasil apabila meluputi dua aspek, yaitu kuantitatif dan kualitatif. Sedangkan, menurut (Moeheriono, 2012) kinerja adalah gambaran pencapaian program kerja dalam mewujudkan visi, misi, tujuan, dan sasaran perusahan. Kinerja adalah hasil dari indikator-indikator pekerjaan dalam waktu tertentu (Wirawan, 2012). 


\section{Dimensi dan Indikator Kinerja Karyawan}

Kinerja individu maupun kelompok dalam perusahaan menggambarkan kinerja perusahaan itu sendiri. Hal-hal yang dapat mempengaruhi standar kinerja (Mangkunegara, 2011):

1. Kompetensi

Yaitu kemanpuan dan keterampilan seseorang pekerja dalam melakukan pekerjaannya, terdiri atas:

a) Menurut (Robbins \& Judge, 2014) kesehatan jiwa dan raga individu, pendidikan, pengalaman dan pelatihan yang pernah didapatan selama bekerja dapat meningkatkan keterampilan dan kemampuan kerja karyawan. Kemampuan artinya kemampuan seseorang untuk melakukan dan menyelesaikan berbagai tugas dalam suatu pekerjaan.

b) Menurut (Hasibuan, 2017) keahlian dapat menunjukkan kemampuasn sesorang untuk menyelesaikan suatu pekerjaan. Keahlian dapat berupa conceptual skill, technical skill, human skill, serta kemampuan untuk memanfaatkan kesempatan dalam menggunakan teknologi yang dimiliki perusahaan untuk mencapai tujuan.

2. Dukungan Organisasi

Lingkungan organisasi dalam bentuk persepsi terhadap pekerjaan, attitude yang dibangun dalam lingkungan kerja, personality, pembelajaran terhadap gagasan dan ide baru di dalam pekerjaan, serta motivasi diri agar dapat meningkatkan kinerja.

3. Dukungan Manajemen

Suatu oraganisasi sangat bergantung kepada peran pimpinannya dalam membangun kinerja organisasi maupun individu yang ada didalamnya. Diantaranya bagaimana dia mampu melakukan hubungan yang harmonis dengan bawahannya, membuat sistem kerja yang kondusif, dapat memobilisasi seluruh karyawannya sehingga dapat bekerja dengan optimal.

Indikator kinerja dibagi menjadi tiga (Mangkunegara, 2002):

1) Kualitas Kerja

Mengacu pada kualitas SDM yang dimilikinya seperti knowledge, skill, dan ability yang dimiliki seorang karyawan

2) Kuantitas Kerja

Dengan menunjukkan kemampuan prusahaan dalam mengelola SDM, sehingga perusahaan dapat mencapai target yang diharapkan, misalnya target penjualan.

3) Waktu Kerja

Perusahaan dapat menetapkan waktu kerja untuk semua level manajemen secara efektif dan efisien.

4) Kerjasama dengan Rekan Kerja.

Perlu adanya kerjasama dan kepercayaan antar individu yang terlibat dan berkepentingan agar tujuan perusahaan dapat tercapai.

\section{Kaitan EI dan LMX dengan EP}

Menurut Pendapat (Zeidner, Matthews, \& Roberts, 2004) EI memiliki hubungan positif dan negatif dengan kinerja. Sedang (Chiva \& Alegre, 2008) berpendapat bahwa hubungan yang terjadi tersebut dikarenakan sampel yang diambil berasal dari kelompok individu yang memiliki tingkat pekerjaan yang tinggi. Dalam beberapa penelitian yang telah dilakukan terhdap EI dan EP telah diketahui bahwa $E I$ berpengaruh secara positif dan signifikan terhadap EP (Akimas \& Bachri, 2016; Hidayati, Purwanto, \& Yuwono, 2008; Risma, 2012; Setyaningrum, Utami, \& Ruhana, 2016), sedangkan berdasarkan hasil penelitian (Yani \& Istiqomah, 2016) menunjukkan bahwa EI berpengaruh negatif dan tidak signifikan terhadap EP. Sedangkan penelitian (Duwit, 2015) menunjukkan bahwa EI tidak berpengaruh terhadap $E P$.

Dalam penelitian (Firdaus, 2017; Justina, Susetyo, \& Kananlua, 2019; Kambu, Troena, Surachman, \& Setiawan, 2012; Pratikna, 2015) (Arsintadiani \& Harsono, 2002) telah membuktikan jika $L M X$ berpengaruh secara positif terhadap EP. Penelitian terdahulu menyatakan bahwa selain mempererat hubungan antara atasan dengan bawahan, $L M X$ juga mempengaruhi $E P$.

\section{Hipotesis dan Model Penelitian}

Penulis merumuskan hipotesis penelitian yaitu:

H1 : $\quad E I$ berpengaruh terhadap $E P$

$\mathrm{H} 2$ : $\quad L M X$ berpengaruh $E P$

H3 : $E I$ dan $L M X$ berpengaruh terhadap $E P$

Berdasarkan hipotesis di atas, maka model penelitian disusun seperti gambar 2 . 


\section{Gambar 2.} Model

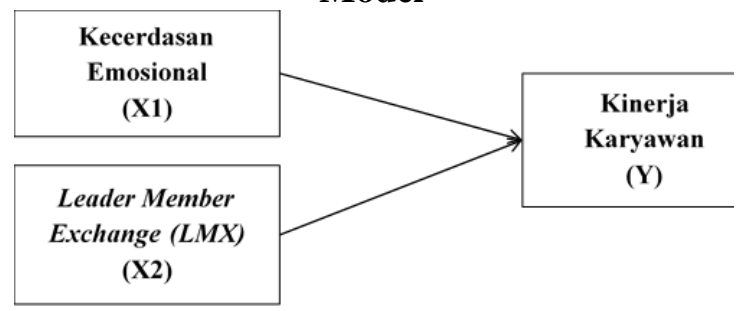

Sumber: hasil olahan Penulis, 2020

\section{METODE PENELITIAN}

Data dikumpulkan dengan metode survey melalui kuesioner yang didistribusikan dengan menggunakan pendekatan self-administered. Untuk mengukur item pernyataan yang ada dalam kuesioner, skala likert dengan lima tingkat persetujuan digunakan untuk mengukur mulai dari sangat tidak setuju sampai dengan sangat setuju.

Populasinya adalah karyawan sales unit Auto 2000 Asia Afrika Bandung sebanyak 30 orang, sehingga digunakan sampel jenuh. Analisis data menggunakan regresi linier berganda yang sebelumnya telah dilakukan uji validitas dan reliabilitas serta uji asumsi klasik, dimana didapatkan hasilnya adalah valid dan reliabel.

\section{HASIL DAN PEMBAHASAN}

Hasil penelitian menunjukkan responden sebanyak $83 \%$ berjenis kelamin laki-laki yang berusaia antara 26-30 tahun (50\%), pendidikan terahir S1 (60\%) dan memiliki masa kerja >1 tahun $(70 \%)$.

\section{Gambaran EI}

Berdasarkan Tabel 1 dapat diketahui bahwa penilaian variabel EI pada karyawan sales unit Auto 2000 Asia Afrika Bandung berada pada kategori baik secara keseluruhan, dan diantara ke lima indikator EI motivasi memiliki persentasi terbesar.

Tabel 1.

Hasil Deskriptif Variabel X1

\begin{tabular}{|l|l|l|l|l|}
\hline No. & \multicolumn{1}{|c|}{ Indikator } & Nilai Total & $\begin{array}{l}\text { Rata-Rata } \\
\text { Skor Total }\end{array}$ & Persentase \\
\hline 1. & Kesadaran Diri & 235 & 117,5 & $78,3 \%$ \\
\hline 2. & Pengendalian Diri & 216 & 108 & $71,9 \%$ \\
\hline 3. & Motivasi & 258 & 129 & $85,9 \%$ \\
\hline 4. & Empati & 244 & 122 & 81,3 \\
\hline 5. & Keterampilan Sosial & 249 & 124,5 & 82,9 \\
\hline \multicolumn{2}{|c|}{ Skor Total } & \multicolumn{3}{|c|}{$\mathbf{1 2 0 2}$} \\
\hline \multicolumn{3}{|c|}{ Rata-Rata Skor Total } & \multicolumn{3}{|c|}{$\mathbf{8 0 . 0 6 \%}$} \\
\hline \multicolumn{2}{|c|}{ Rata-Rata \% } & \multicolumn{3}{|c|}{} \\
\hline
\end{tabular}

Sumber: hasil olahan Penulis, 2020

Hal tersebut mengandung pengertian bahwa agar EI yang dimiliki oleh karyawan dapat terus terpupuk dengan baik, maka perusahaan perlu membuat motivasi-motivsi positif yang dapat membangun karyawan sehingga semangat dalam bekerja dengan $E I$ yang positif.

\section{Gambaran $L M X$}

Tabel 2 menunjukkan penilaian $L M X$ pada karyawan sales unit Auto 2000 Asia Afrika Bandung secara keseluruhan berada pada kategori baik, dan affect merupakan indikator terbesar dibandingkan dengan empat indikator lainnya.

Tabel 2.

Hasil Deskriptif Variabel X2

\begin{tabular}{|l|l|l|l|l|}
\hline No. & \multicolumn{1}{|c|}{ Indikator } & Nilai Total & $\begin{array}{c}\text { Rata-Rata } \\
\text { Skor Total }\end{array}$ & Persentase \\
\hline 1. & Professional Respect & 237 & 118,5 & $79 \%$ \\
\hline 2. & Loyalty & 217 & 108,5 & $72,3 \%$ \\
\hline 3. & Affect & 366 & 122 & $81,3 \%$ \\
\hline 4. & Contribution & 346 & 115 & $76,8 \%$ \\
\hline \multicolumn{3}{|c|}{ Skor Total } & \multicolumn{3}{c|}{$\mathbf{1 1 6 6}$} \\
\hline \multicolumn{3}{|c|}{ Rata-Rata Skor Total } & \multicolumn{3}{c|}{} \\
\hline \multicolumn{3}{|c|}{ Lanjutan Tabel Hasil Rekapitulasi Variabel Leader Member } \\
\hline \multicolumn{3}{|c|}{ Exchange (X2) } \\
\hline
\end{tabular}

Sumber: Penulis, 2020

Ini mengandung pengertian bahwa hubungan timbal balik antara karyawan dengan atasannya memiliki peran saling mempengaruhi dalam lingkungan pekerjaan, dismaping peran-peran lainnya seperti saling menghormati dalam hal profesionalisme kerja.

\section{Gambaran EP}

Tabel 3 menunjukan bahwa EP sales unit Auto 2000 Asia Afrika Bandung berada pada kategori baik secara keseluruhan. Diantara ke empat indokatornya, indikator kualitas kerja memiliki persentasi terbesar $(88,4 \%)$.

\section{Tabel 3.}

Hasil Deskriptif Variabel Y

\begin{tabular}{|l|l|l|l|l|}
\hline No. & \multicolumn{1}{|c|}{ Indikator } & Nilai Total & $\begin{array}{l}\text { Rata-Rata } \\
\text { Skor Total }\end{array}$ & Persentase \\
\hline 1. & Kualitas Kerja & 356 & 119 & $88,4 \%$ \\
\hline 2. & Kuantitas Kerja & 362 & 121 & $80,4 \%$ \\
\hline 3. & Waktu Kerja & 346 & 115 & $76,8 \%$ \\
\hline 4. & Kerjasama & 345 & 115 & $76,6 \%$ \\
\hline \multicolumn{3}{|c|}{ Skor Total } & \multicolumn{3}{|c|}{$\mathbf{3 5 2}$} \\
\hline \multicolumn{2}{|c|}{ Rata-Rata Skor Total } & $\mathbf{3 0 , 5 5 \%}$ \\
\hline
\end{tabular}

Sumber: Penulis, 2020

Artinya, kualitas kerja memiliki peran yang cukup dominan dalam menentukan baik tidaknya EP sales unit Auto 2000 Asia Afrika Bandung. 
Pengaruh Antar Variabel yang Diteliti

Berdasarkan hasil uji analisis, maka hasilnya adalah:

Tabel 4.

Analisis Regresi Linier Berganda

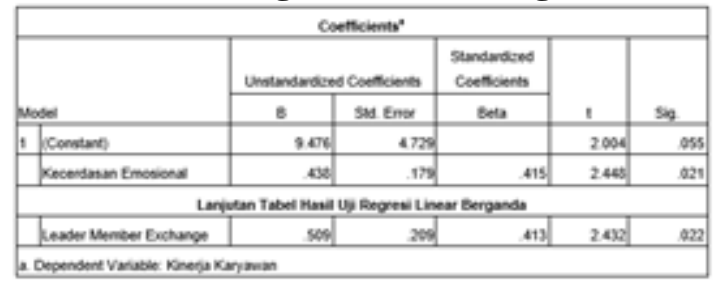

Sumber: Penulis, 2020

Artinya:

a) Nilai konstan 9,476 mengandung pengertian jika seluruh variabel independen dianggap konstan, yaitu EI dan $L M X$, maka nilai $E P$ akan sebesar 9,476

b) Variabel EI memiliki nilai koefisien 0,438 (positif) yang artinya jika ada penambahan pada $E I$ akan meningkatkan $E P$ di Auto 2000 Asia Afrika sebesar 0,438 dengan anggapan $L M X$ tetap.

c) Variabel $L M X$ memiliki nilai koefisien 0,509 (positif) yang artinya jika ada penambahan pada $L M X$ akan meningkatkan EP di Auto 2000 Asia Afrika sebesar 0,509 dengan anggapan $E I$ tetap.

Sedangkan kontribusi untuk kedua variabel $\mathrm{X}$ terhadap Y sebagai berikut:

Tabel 5.

Analisis Regresi Linier Berganda Model Summary"

\begin{tabular}{|l|r|r|r|c|}
\hline & & & \multicolumn{4}{|c|}{ Model Summary" } \\
\hline Model & R & R Square & \multicolumn{1}{c|}{$\begin{array}{c}\text { Adjusted R } \\
\text { Square }\end{array}$} & $\begin{array}{c}\text { Std. Error of the } \\
\text { Estimate }\end{array}$ \\
\hline 1 & $.757^{2}$ & .573 & 542 & 4.218 \\
\hline
\end{tabular}

a. Predictors: (Constant), Leader Member Exchange, Kecerdasan Emosional

b. Dependent Variable: Kinerja Karyawan

Sumber: Penulis, 2020

Hasil R Square menunjukkan angka 0,573 atau sama dengan $57,3 \%$ atau pengaruhnya kuat (Cahyani, Rumapea, \& Liando, 2017), artinya sebesar $57,3 \%$ variabel EI dan LMX memberikan pengaruh dan sisanya $42,7 \%$ dipengaruhi oleh faktor-faktor lain yang tidak diteliti.

\section{Hasil Uji Hipotesis}

Dilakukan secara parsial dan simultan terhadap variabel-variabel yang diteliti.

Tabel 6.
Hasil Uji T Parsial

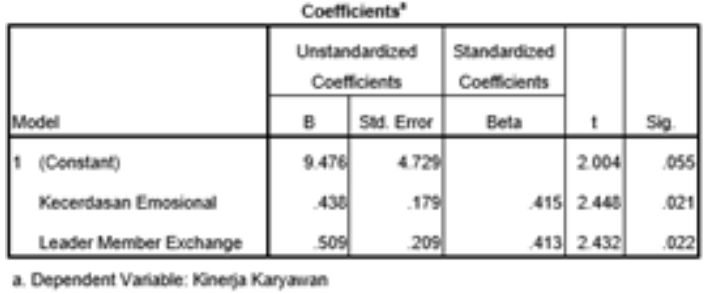

Sumber: hasil olahan Penulis, 2020

Dengan pengujian pihak sebelah kanan dari tingkat signifikansi 5\% maka di dapat ttabel sebesar 1,703. Hal ini berarti thitung 2,448 > ttabel 1,703, artinya hipotesis diterima. Mengandung pengertian bahwa ada pengaruh antara EI dengan EP pada Auto 2000 Asia Afrika Bandung, dengan taraf signifikansi pada uji F di atas menunjukkan taraf Sig-nya berada di bawah 0,05 atau sebesar 0,021 yang artinya ada pengaruh signifikan antara $E I$ dengan $E P$. Begitu pula hanya dengan $L M X$ memiliki thitung $2,432>$ ttabel 1,703. Hal ini mengandung pengertian terdapat pengaruh dan signifikan antara $L M X$ dengan $E P$.

Pengujian hipotesis juga dilakukan secara simultan dan didapatkan hasil:

Tabel 7.

Hasil Uji F Simultan

\begin{tabular}{|l|r|r|r|r|r|}
\hline Model & Sum of Squares & df & Mean Square & F & Sig. \\
\hline $1 \quad$ Regression & 645.585 & 2 & 322.793 & 18.140 & .000 \\
Residual & 480.454 & 27 & 17.795 & & \\
\multicolumn{1}{|l|}{ Total } & 1126.039 & 29 & & & \\
\hline
\end{tabular}
a. Predictors. (Constant), Leader Member Exchange, Kecerdasan Emosional
b. Dependent Variable: Kinerja Karyawan

Sumber: hasil olahan Penulis, 2020

Dapat dilihat bahwa nilai Fhitung sebesar 18,140. Nilai Ftabel 30 responden dengan taraf signifikansi 5\% dan didapat Ftabel 3.35 dan Fhitung $=18.140$. Dikarenakan Fhitung $>$ Ftabel maka dapat disimpulkan bahwa EI dan $L M X$ berpengaruh signifikan terhadap EP. Dengan demikian, hipotesis ketiga diterima.

\section{KESIMPULAN}

EI dan LMX berpengaruh secara signifikan dan positif terhadap EP pada Auto 2000 Asia Afrika.

\section{REFERENSI}

Akimas, H. N., \& Bachri, A. A. (2016). Pengaruh Kecerdasan Intelektual (IQ), Kecerdasan Emosional (EQ), Kecerdasan Spiritual (SQ) terhadap Kinerja Pegawai Inspektorat Provinsi Kalimantan Selatan. Jurnal Wawasan Manajemen, 4(3), 259-272.

Arsintadiani, D., \& Harsono, M. (2002). Pengaruh 
Tingkat LMX terhadap Penilaian Kinerja dan Kepuasan Kerja dengan Kesamaan Jender dan Locus of Control sebagai Variabel Moderator. Persepektif, 7(2), 113122.

Cahyani, N. L. P. A., Rumapea, P., \& Liando, D. M. (2017). Pengaruh Kecerdasan Emosional, Motivasi, Dan Pelatihan Terhadap Kinerja Aparatur Sipil Negara Di Biro Umum Sekretariat Daerah Provinsi Sulawesi Utara. Jurnal Politico, 6(1).

Chiva, R., \& Alegre, J. (2008). Emotional Intelligence and Job Satisfaction: The Role of Organizational Learning Capability. Personnel Review, 37(6), 680-701. https://doi.org/10.1108/004834808109069 00

Ciarrochi, J. V., \& Kashdan, T. B. (2013). The Foundations of Flourishing. In J. V. Ciarrochi \& T. B. Kashdan (Eds.), Mindfulness, Acceptance, and Positive Psychology: The Seven Foundation of Well-Bing (p. 36). Oakland, CA: Context Press.

Duwit, F. (2015). Pengaruh Kompetensi Komunikasi, Kecerdasan Emosional, dan Budaya Organisasi terhadap Kinerja Pegawai (Studi Pada Badan Pemberdayaan Masyarakat dan Pemerintahan Kampung Kabupaten Raja Ampat Propinsi Papua Barat). Jurnal EMBA, 3(4), 130-141.

Farahbod, F., Azadehdel, M., Rezaei-Dizgah, M., \& Nezhadi-Jirdehi, M. (2012). Organizational Citizenship Behavior: The Role of Organizational Justice and LeaderMember Exchange. Interdisciplinary Journal of Contemporary Research in Business, 3(9), 893-903.

Fauziah. (2015). Hubungan Kecerdasan Emosional dengan Prestasi Belajar Mahasiswa Semester II Bimbingan Konseling UIN Ar-Raniry. Jurnal Ilmiah Edukasi, 1(1), 90-98.

Firdaus, R. M. (2017). Pengaruh Modal Sosial dan Leader Member Exchange terhadap Kinerja Melalui Komitmen Organisasional. Buletin Bisnis \& Manajemen, 03(02), 1-13.

Graen, G. B., \& Uhl-Bien, M. (1995). Relationship-Based Approach to Leadership: Development of LeaderMember Exchange (LMX ) Theory of Leadership over 25 Years: Applying a Multi-Level Multi-Domain Perspective. Management Department Faculty Publications, 6(2), 219-247. Retrieved from

https://digitalcommons.unl.edu/cgi/viewcont ent.cgi $?$ article $=1059 \&$ context $=$ managementf acpub

Hanzaee, K. H., \& Mirvaisi, M. (2013). Management Science Letters. Management Science Letters, 3, 1395-1402. https://doi.org/10.5267/j.msl.2013.04.010

Hidayati, R., Purwanto, Y., \& Yuwono, S. (2008). Kecerdasan Emosi, Stres Kerja dan Kinerja Karyawan. Jurnal Psikologi, 2(1), 91-96.

Ibrahim, R. M., Ghani, M. A., \& Salleh, A. M. M. (2013). Elevating Organizational Citizenship Behavior among Local Government Employees: The Mediating Role of Job Satisfaction. Canadian Center of Science and Education, 9(13), 92-104. https://doi.org/10.5539/ass.v9n13p92

Ilies, R., Nahrgang, J. D., \& Morgeson, F. P. (2007). Leader-Member Exchange and Citizenship Behaviors: A Meta-Analysis. Journal of Applied Psychology, 92(1), 269$277 . \quad$ https://doi.org/10.1037/00219010.92.1.269

Indarjanti, P., \& Bodroastuti, T. (2012). Pengaruh Kemampuan, Usaha dan Dukungan Organisasi Terhadap Kinerja. Jurnal Kajian Akuntansi Dan Bisnis, 1, 64-83. Retrieved from

http://jurnal.widyamanggala.ac.id/index.php /wmkeb/article/view/15/12

Justina, S., Susetyo, S., \& Kananlua, P. (2019). Pengaruh Leader-Member Exchange terhadap Kinerja Karyawan Melalui Peran Variabel Mediasi Work Engagement Pada PT. Perusahaan Listrik Negara (Persero) Area Bengkulu. Managament Insight: Jurnal Ilmiah Manajemen, 14(1), 51-62. https://doi.org/10.33369/insight.14.1.51-62

Kambu, A., Troena, E. A., Surachman, \& Setiawan, M. (2012). Pengaruh LeaderMember Exchange, Persepsi Dukungan Organisasional, Budaya Etnis Papua dan Organizational Citizenship Behavior, terhadap Kinerja Pegawai pada Sekda Provinsi Papua. Jurnal Aplikasi Manajemen, 10(2), 262-272.

Kasmawati. (2018). Sumber daya manusia sebagai sumber keunggulan kompetitif. Jurnal Idaarah, II(2), 229-242.

Latief, B. (2012). Faktor-faktor yang Mempengaruhi Kinerja Karyawan PT Mega Mulia Servindo di Makasar. Jurnal Manajemen Dan Akuntansi, 1(2), 61-70.

Lengkong, J. S., Lapian, J., \& Lengkong, V. 
(2016). Analisis Peran Kualitas Interaksi Atasan dan Bawahan Terhadap Organizational Citizenship Behavior Berdasarkan Persepsi Pegawai di Dinas Pendidikan Nasional Provinsi Sulawesi Utara. Jurnal Berkala Ilmiah Efisiensi, 16(04), 864-870.

Pambudi, R. (2014). Pengaruh Faktor-faktor Kecerdasan Emosional Terhadap Kinerja Pegawai (Studi Pada Pegawai BAPPEDA Kota Semarang). Universitas Dipenogoro.

Pratikna, R. N. (2015). Leader-Member Exchange Sebagai Pemoderator Dalam Pengaruh Kepemimpinan Transformasional Terhadap Persepsi Tentang Rasa Keadilan Organisasional: Studi Literatur. Bina Ekonomi, 19(2), 105-114. https://doi.org/10.26593/be.v19i2.1482.10 5-114

Risma, D. (2012). Pengaruh Kecerdasan Emosional Terhadap Kinerja Karyawan: Penelitian Eksperimen. EDUCHILD, 01(1), 86-97. Retrieved from http://stiepena.ac.id/wpcontent/uploads/2012/11/pena-fokus-vol-4no-2-40-45.pdf

Rouf, M. (2018). Analisis Pekerjaan Sumber Daya Manusia (SDM) pada Lembaga Pendidikan Islam. AL-ASASIYYA: Journal Basic of Education, 02(02), 44-64.

Setiawan, R. I. (2016). Pengembangan Sumber Daya Manusia di Bidang Pariwisata: Perspektif Potensi Wisata Daerah Berkembang. Jurnal Penelitian Manajemen Terapan (PENATARAN), 1(1), 23-35.

Setyaningrum, R., Utami, H. N., \& Ruhana, I. (2016). Pengaruh Kecerdasan Emosional terhadap Kinerja (Studi Pada Karyawan PT. Jasa Raharja Cabang Jawa Timur). Jurnal Administrasi Bisnis (JAB), 36(1), 211-220.

Saleh, D. S., \& Imbari, S. (2019). KAJIAN PRODUCTION EMPHASIS, PENGEMBANGAN KARIR PROTEAN, DAN KOMPENSASI SOSIAL PADA KINERJA KARYAWAN DENGAN KEPUASAN KERJA SEBAGAI VARIABEL MEDIASI. Eqien: Jurnal Ekonomi dan Bisnis, 6(2), 17-27.

Sumiyarsih, W., Mujiasih, E., \& Ariati, J. (2012). Hubungan Antara Kecerdasan Emosional Dengan Organizational Citizenship Behavior ( OCB ) Pada Karyawan CV. Aneka Ilmu Semarang. Jurnal Psikologi Undip, 11(1), 19-27.

Supit, Y. A., Suryawati, C., \& Sriatmi, A. (2015).
Dampak Pergantian Pemimpin terhadap Situasi Kerja Dinas Kesehatan Kota Jayapura Provinsi Papua. Jurnal Manajemen Kesehatan Indonesia, 03(03), 186-193.

Suprihati. (2014). Analisis Faktor-faktor Yang Mempengaruhi Kinerja Karyawan Perusahaan Sari Jati Di Sragen. Jurnal Paradigma, 12(01), 93-112.

Suryana, A. K. H. (2014). Pengaruh Kecerdasan Emosional dan Leader Member Exchange (LMX) terhadap Organizational Citizenship Behavior (OCB) dengan Kepuasan Kerja Sebagai Variabel Mediasi. Universitas Sebelas Maret, Surakarta.

Wardhana, R. M. D. H., Tarmedi, E., \& Sumiyati. (2016). Upaya Meningkatkan Kinerja Dengan Cara Memberikan Motivasi Kerja dan Menumbuhkan Komitmen Organisasional Pegawai Dinas Perhubungan Provinsi Jawa Barat. Journal of Business Management Education, 1(2), 91-96.

Winarno, J. (2008). Emotional Intelligence sebagai Salah Satu Faktor Penunjang Prestasi Kerja. Jurnal Manajemen, 8(1), 12-19.

Yani, A. S., \& Istiqomah, A. (2016). Pengaruh Kecerdasan Intelektual dan Kecerdasan Emosional Terhadap Kinerja Karyawan Dengan Profesionalisme Sebagai Variabel Intervening (Studi Empiris Terhadap PT. JNE Service Center Utara 1). Media Studi Ekonomi, 19(2), 43-55.

Yunus, N. H., Ishak, N. A., Mustapha, R. M. R., \& Othman, A. K. (2010). Displaying Employees' Organizational Citizenship Behaviour at The Workplace: The Impack of Superior's Emotional Intelligence and Moderating Impack of Leader-Member Exchange. Vision, 14(1-2), 13-23.

Zeidner, M., Matthews, G., \& Roberts, R. D. (2004). Emotional intelligence in the workplace: A Critical Review. Applied Psychology: An International Review, 53(3), 371-399. https://doi.org/10.1111/j.14640597.2004.00176.x 